\title{
Design and analysis of disc brake system in high speed vehicles
}

\author{
Anil Babu Seelam, Nabil Ahmed Zakir Hussain, and Sachidananda Hassan Krishanmurthy ${ }^{*}$ \\ School of Engineering and IT, Manipal Academy of Higher Education, Dubai 345050, UAE
}

Received: 19 April 2021 / Accepted: 10 August 2021

\begin{abstract}
Brakes are the most important component of any automobile. Brakes provide the ability to reduce or bring automobile to a complete stop. The process of braking is usually achieved by applying pressure to the brake discs. The main objective of this research paper is to propose an appropriate design and to perform analysis of a suitable brake rotor to enhance the performance of the high-speed car. The design of the brake disc is modelled using Solid works and the analysis is carried out using Ansys software. The analysis has been conducted by considering stainless steel and grey cast iron using same brake rotor design so that optimal choice of brake disc can be considered. The analysis considered involves static structural analysis and steady state thermal analysis considering specific parameters on brake rotor to increase the life of brake rotor. From the analysis it is found that the performance and life of disc brake depends upon heat dissipation. From the analysis results it can be concluded that grey cast iron has performed better as compared to stainless steel as this material has anti-fade properties which improves the life of the brake rotor.
\end{abstract}

Keywords: Disc brake system / high speed / static analysis / thermal analysis / deformation

\section{Introduction}

Disc brakes are commonly used in automobile applications [1] and it uses calipers to apply pressure against a disc or rotor to create friction [2-4]. They can stop the vehicle in descending roads without wheel lockup and is considered better than other types of brakes [5]. Using rotor size, it is possible to adjust braking power as per the requirement. So, in this research paper, design and selection of proper material has been studied to select brake setup by changing the rim size from 16 inch to 17 inch. Some of the literature review has been referred on the disc brakes and presented as follows. Subhasis et al. [6] have studied temperature distribution using FEA in case of disc brake. Their main objective was to study distribution of temperature of rotor disc and to identify critical temperature considering convection and radiation parameters for Asbestos, AMMC (Aluminum metal matrix composites) and GCI (Grey cast iron) materials. They concluded that heat generation is less in case of AMMC material as compared to GCI. AMCC material can be used as a suitable alternative material because of its lower density and higher thermal conductivity $[7,8]$. Dakhil et al. [9] have studied performance of disc brake system by considering cast iron and stainless-steel material. They studied the temperature distribution, stresses, and deformation in case of disc brake using finite

\footnotetext{
* e-mail: sachidananda6@gmail.com
}

element analysis. They concluded by giving the maximum displacement diagrams for both cast iron and stainlesssteel. Dhir [10] have studied temperature distribution in case of disc brake system at time of braking to study durability of the disc using finite element method. They concluded by performing durability studies considering thermo-mechanical cyclic stresses to study fatigue factor of safety. Belhocine and Bouchetara [11] have studied temperature and thermal stress disc brake using grey cast iron material. They studied thermo-structural analysis and von mises stresses in the disc using ANSYS. They concluded by comparing the results obtained from previous studies. Nouby et al. [12] have studied disc brake materials considering heavy duty performance which is commonly used in racing cars. Wheel hub and steering knuckle have been studied considering FE model and validated using experimental modal analysis. They concluded that pad friction material contributes more to the system instability of the racing cars. Bhat and Lee [13] have studied optimization of the disc brake system to improve the heat dissipation. They used Taguchi method for various ventilation parameters considering rotor hole diameter, number of slots and no of rotor holes. They arrived at optimal design based on Taguchi method considering the above parameters and they concluded that number of ventilation slots played a major role in heat dissipation performance of the disc brake system. Vidiya and Singh [14] have studied formula racing car design brake system. They studied thermal analysis considering conversion of 
kinetic energy into brake's heat energy. They concluded that simulation data and reading taken from the car testing was accurate and reliable. Chopade and Valavade [15] have studied experimentally thermal performance of a disc brake rotor using CFD. They studied mass flow rate and heat dissipation of a brake rotor. They concluded that maximum deviation of the numerical results and experimentally results were small. Yevtushenko and Kuciej [16] have studied a two-element model of a braking system consisting of a pad sliding with time dependent velocity. They investigated temperature and thermal stresses of a ceramic metal strip. They concluded that their results can be used in modelling thermal cracking of the element used in braking system. Grzes [17] have studied maximum temperature in brake disc under repeated braking applications. They studied braking system using heat dynamics equations of friction and wear. He concluded that flash temperature was high at the beginning and then gradually decreased. Gijan [18] have studied brake disc design by parametric evaluation for heavy vehicles. They studied thermomechanical performances using simulation approach to increase the fatigue life of the bearing. They concluded that instead of straight vanes if the pillar arrangement was made then it is possible to increase the fatigue life of the brakes. Yevtushenko and Grzes [19,20] have studied disc brake using spatial computational model. They studied temperature dependent coefficient of friction by considering contact temperature and vehicle velocity. They concluded by giving optimal design for a brake pad material. Garcia-leon and Florez-solano [21] have studied disc brake system to analyze dynamics and kinematics of the brake system to simulate using FEA. They concluded that using geometry it is possible to optimize the system which will be great helpful to automotive industries. Nguyen et al. [22] have studied energy dissipation by friction in case of braking system. They studied strategy of storing in steady state using thermal processing discrete element method. They concluded by giving experimental and empirical data by comparing from various literature review. From this literature review it is observed that many researchers have analyzed the brake drum from various material point of view. So, in this research work an attempt have been made to study brake rotor considering martensitic stainless steel and grey cast iron. Grey cast iron is commonly used in light weight vehicles, and it will continue as a choice for brake discs in near future also [23].

\section{Methodology}

To perform the analysis, the following data have been collected such as mass (m) of the vehicle $1000 \mathrm{~kg}$, Maximum velocity $(u)$ and minimum velocity $(v)$ of the vehicle considered is $100 \mathrm{~km} / \mathrm{h}$ and $0 \mathrm{~km} / \mathrm{h}$, inner diameter of the brake rotor as $0.240 \mathrm{~m}$, outer diameter of the brake rotor as $0.327 \mathrm{~m}$, coefficient of friction $\mu$ as 0.4 and stopping distance of the vehicle as $34 \mathrm{~m}$.

Maximum frictional force is calculated using the following formulae

$$
F=\mu \mathrm{mg}=4316.4 N .
$$

The maximum kinetic energy attained by the vehicle is given by

$$
K . E=0.5 \mathrm{mV}^{2}=848290.19 \mathrm{~J} .
$$

Deacceleration of the vehicle is given as

$$
a=\left(\frac{v^{2}-u^{2}}{2 S}\right)=11.34 \frac{m}{S^{2}}
$$

Braking force $F$ is given by considering work done $W=$ wd and work done $W=0.5 \mathrm{mV}^{2}=12474 \mathrm{~N}$.

Stopping time or braking time is given as

$$
t=\left(\frac{v-u}{a}\right)=2.44 \mathrm{~s}
$$

Power generated in one rotor $p=Q / t=347659.914$ Watts since $Q=$ kinetic energy.

Heat flux generated $\phi[24]$ is given by

$$
\emptyset=\frac{4 P\left(O . D^{2}-I . D^{2}\right)}{\pi}=0.0218477 \frac{\mathrm{Watt}}{\mathrm{mm}^{2}} .
$$

The heat generation and heat dissipation in case of disc brake arises due to change of kinetic energy into thermal energy which in turn results in heating of the disc brake and the braking power of the disc brake fades at temperature of $600 \mathrm{~K}$. Hence, the film temperature is calculated considering warping temperature and ambient temperature divided by two in this analysis.

Reynold's number Re is given by

$$
R e=\frac{\rho V D}{\mu}=159955.2 .
$$

Nusselt's Number, $\mathrm{Nu}$ is given by:

$$
N u=0.0266 \times R e^{0.805} \times P_{r}^{0.333}=363.95 .
$$

Forced convective heat transfer coefficient, $h$ is given by

$$
h=\frac{(N u . k)}{d}=66.596 \frac{W}{m^{2}} K
$$

Before proceeding with the brake rotor design, the crucial brake requirements such as brakes must be strong enough to retard the motion within a minimum brake system, should have anti fade properties so that they should be effective, and the material selection are made to able to withstand mechanical properties and chemical composition must be retained to prevent fading. So, in this research paper, the Static Structural Analysis and Steady State Thermal Analysis will be performed on the designed brake rotor. This analysis has been carried out using two different materials considering above brake rotor properties, Martensitic Stainless Steel and Grey Cast Iron. Both 
these materials are generally used in the automotive industry because of their high corrosion resistance, ability to retains their mechanical and chemical properties at high temperatures, thermally and electrically stable and affordable costs in the market.

\section{Disc brakes}

\subsection{Design of disc brake system using solid works}

The rotor dimensions considered for the analysis is as shown in Table 1 and the corresponding drawing of the rotor is shown in Figure 1. The rotor has been modelled using solid works and the corresponding meshed geometry (fine mesh) considering 152266 nodes and 88791 elements.

Table 1. Rotor dimensions.

\begin{tabular}{ll}
\hline Width (mm) & 20.57 \\
Diameter (mm) & 325.15 \\
Vane count (No.) & 48 \\
Weight (Kg) & 4.26 \\
Rotor bolt circle & 222.25 \\
Rotor mount hole size & 6.37 \\
Lug ID (mm) & 209.57 \\
Far side inside diameter (mm) & 240.28 \\
\hline
\end{tabular}

\section{Results and analysis}

\subsection{Static structural analysis of disc brake}

The static structural analysis has been performed by applying the following boundary conditions. Fixed supports have been marked and a frictional force of $4316.4 \mathrm{~N}$ has been applied on the outer surface areas of the brake rotors. This analysis has been carried out for both Martensitic Stainless Steel and Grey Cast Iron and the boundary conditions remains same.

The boundary conditions applied is as shown in Figure 2 and the corresponding equivalent elastic strain, stress, shear stress and total deformation analysis have been performed. Figure 3 shows the equivalent elastic strain for both stainless steel and grey cast iron. From these figures it is observed that the maximum strain in case of stainless steel and grey cast iron is 0.0119 and 0.0131 and the minimum strain in both the material is $2.039 \mathrm{e}-5$ and 2.690 $\mathrm{e}-5$. The strain observed in case of stainless steel is less as compared to grey cast iron.

Figure 4 shows the equivalent stress for both stainless steel and grey cast iron. From these figures it is observed that the maximum stress on the rotor is $2302.8 \mathrm{MPa}$ and 1429.4 MPa for stainless steel and grey cast iron, respectively. Also, the minimum equivalent stress is $1.983 \mathrm{MPa}$ and $1.642 \mathrm{MPa}$ is observed in case of stainless steel and grey cast iron. From this it is observed that the maximum stress is less in case of grey cast iron as compared to stainless steel and same type of behavior is also observed in the literature [25-27].

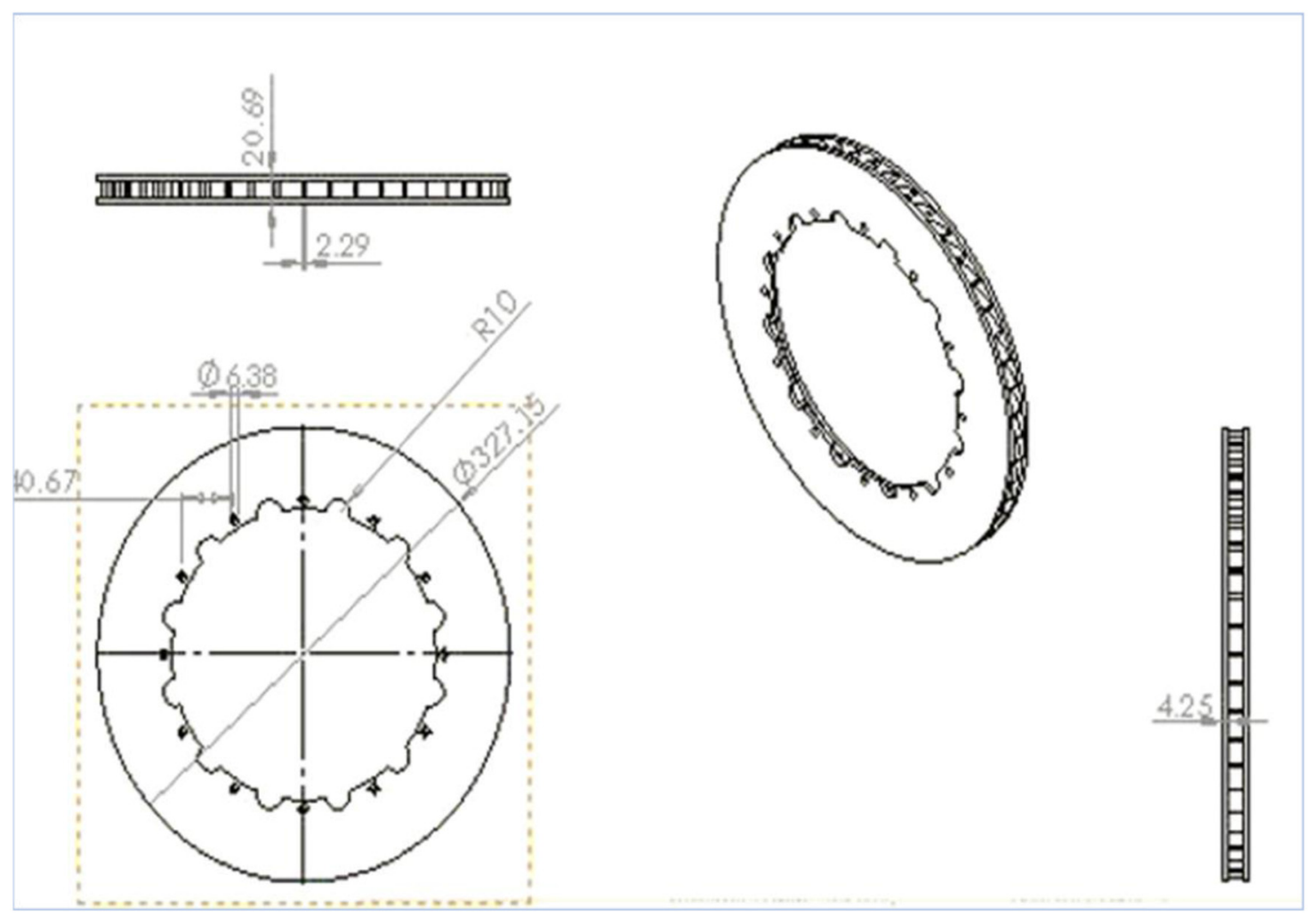

Fig. 1. 2D drawing of Rotor Ventilated disc without bell [24]. 


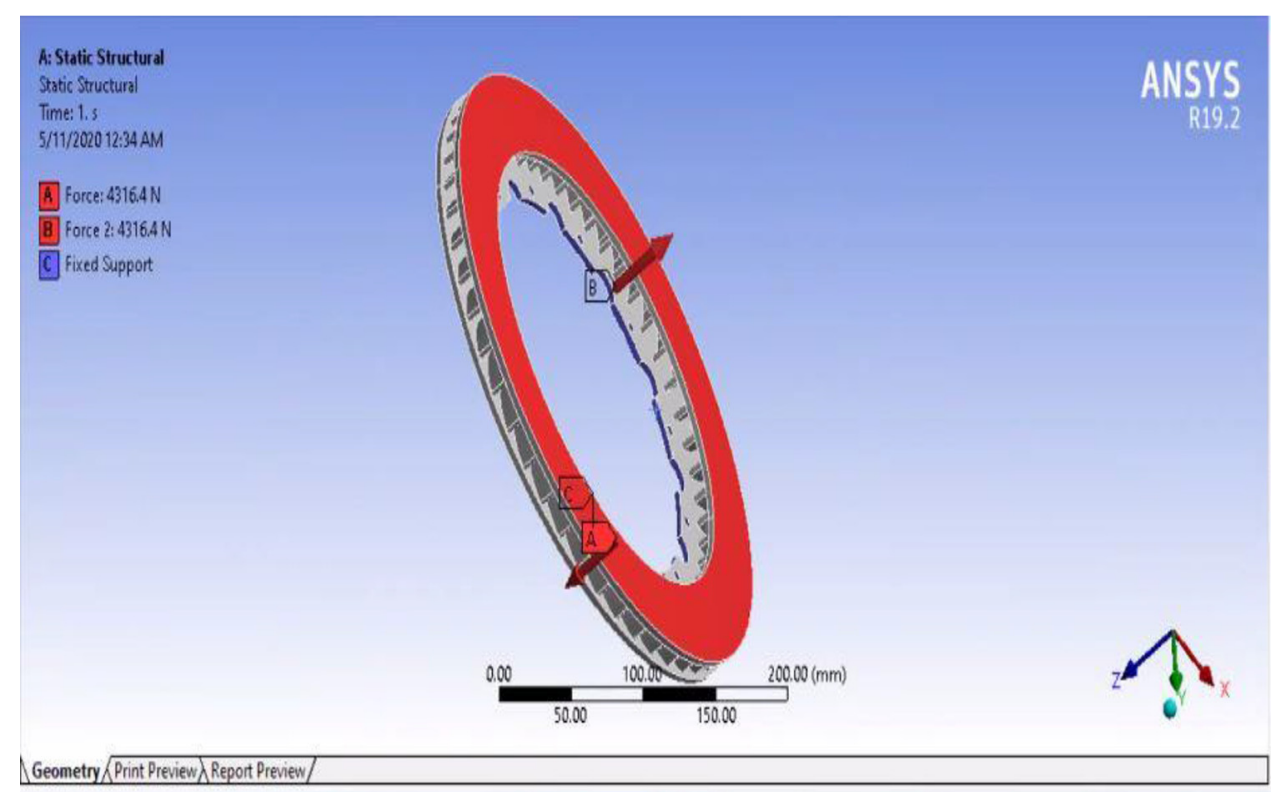

Fig. 2. Boundary Conditions for Static Structural.
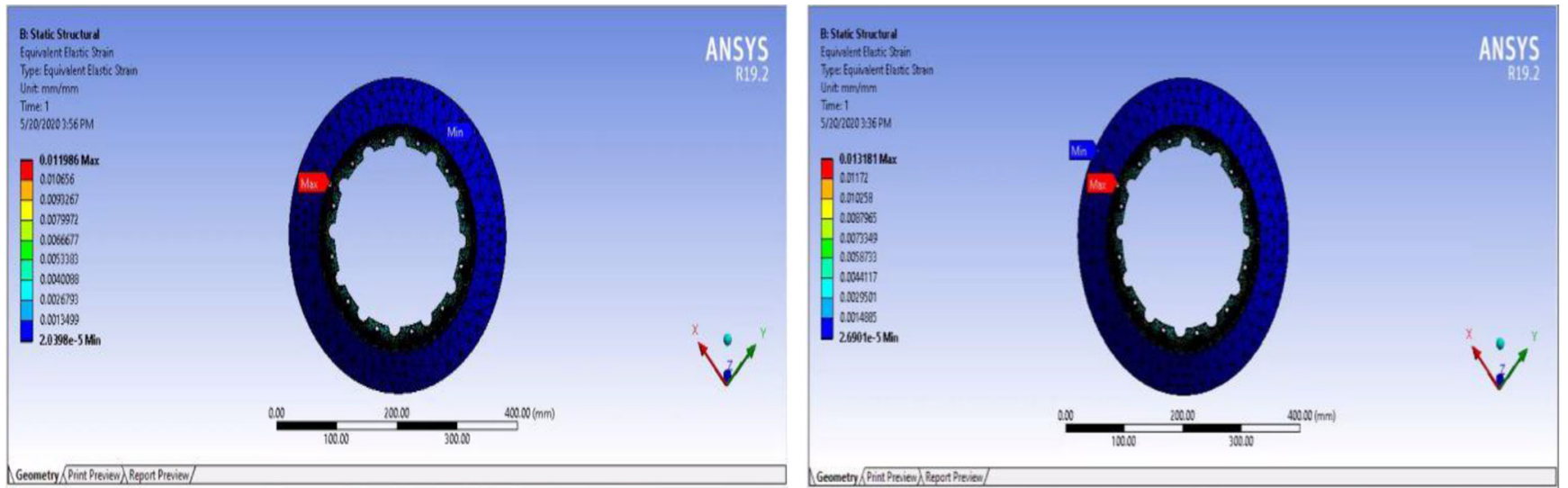

Fig. 3. Equivalent Elastic Strain for SS and GCI.
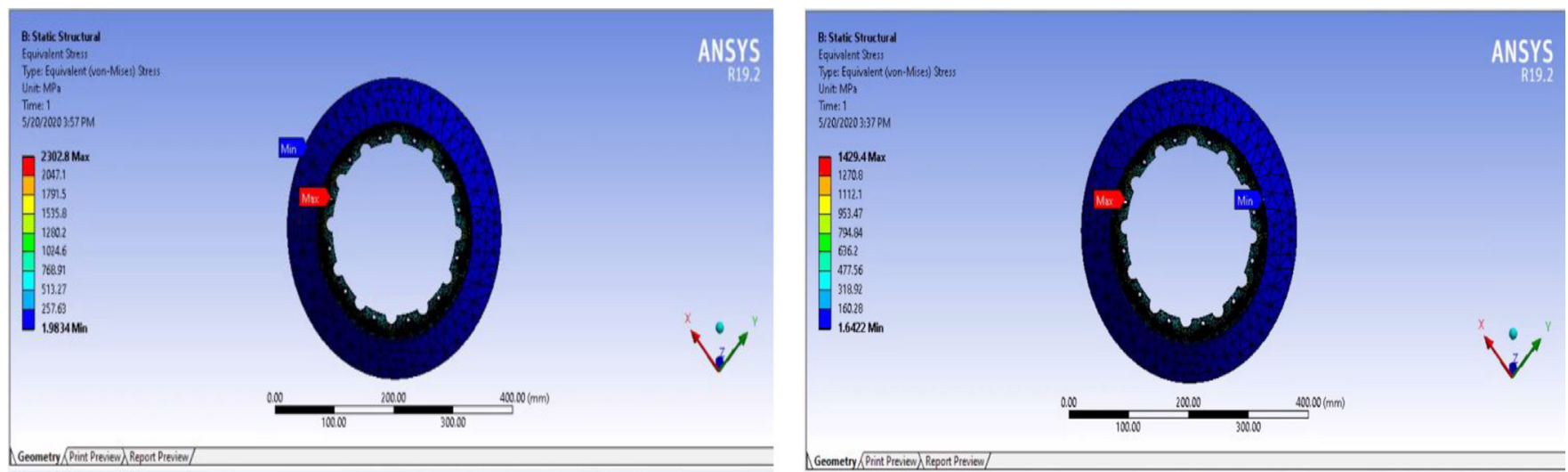

Fig. 4. Equivalent Stress for SS and GCI. 

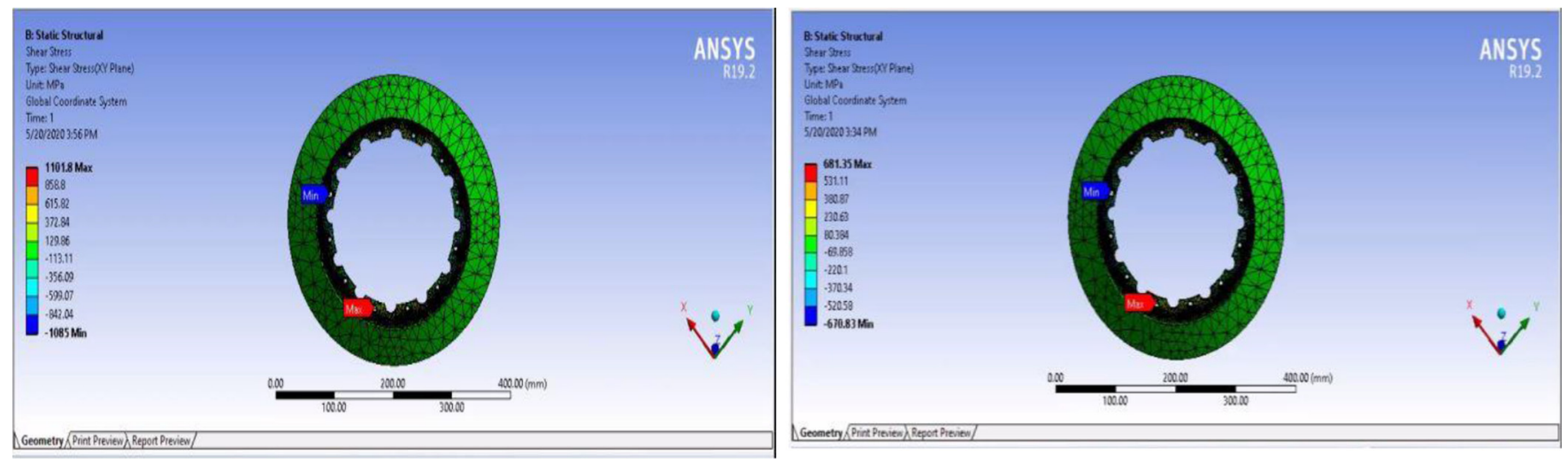

Fig. 5. Shear Stress for SS and GCI.
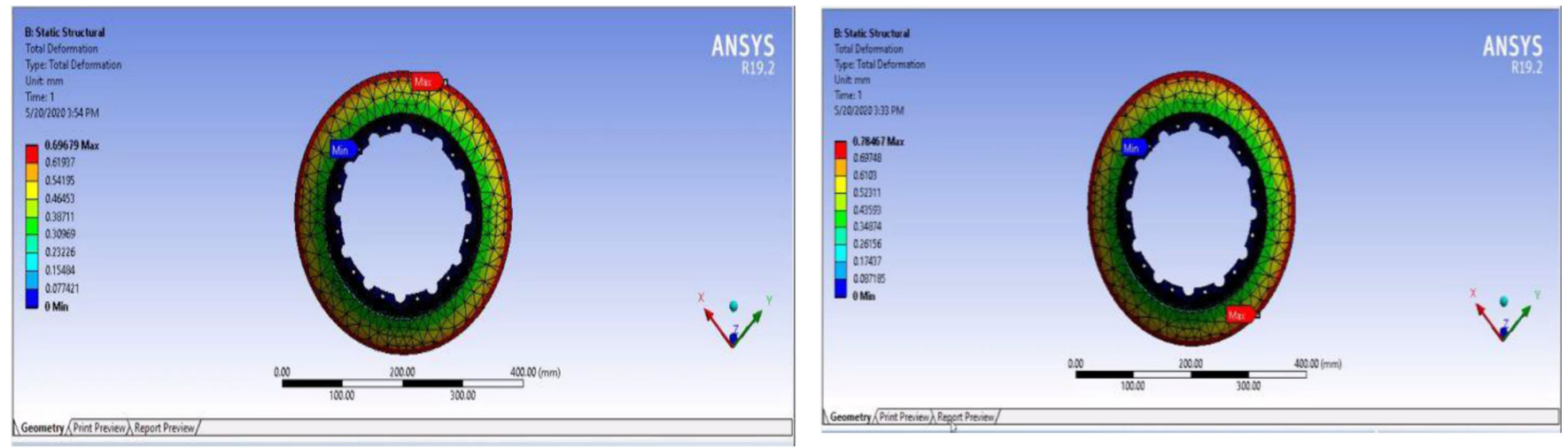

Fig. 6. Total deformation for SS and GCI.

Figure 5 shows the shear stress for both stainless steel and grey cast iron. From this figure it is observed that maximum shear stress in the rotor in case of stainless steel and grey cast iron is $1101.8 \mathrm{MPa}$ and $681.35 \mathrm{MPa}$, respectively. Also, the minimum shear stress observed is $-1085 \mathrm{MPa}$ for stainless steel and $-670.83 \mathrm{MPa}$ for grey cast iron. From this it can be concluded that grey cast iron has performed better as compared to stainless steel from shear stress point of view.

Figure 6 shows the total deformation for rotor in case of stainless steel and grey cast iron is $0.6967 \mathrm{~mm}$ and $0.7846 \mathrm{~mm}$. From this it is observed that stainless steel has performed better as compared to grey cast iron. It is also observed from literature review [26] that stainless steel total deformation is less as compared to grey cast iron.

Figure 7 shows the comparison of equivalent strain, stress, shear stress and total deformation for both stainless steel and grey cast iron. From this figure it is observed that equivalent strain and total deformation in case of grey cast iron is $9.96 \%$ and $12.6 \%$ higher than martensitic stainless steel. Also, it is observed that equivalent stress and shear stress in case of grey cast iron is $38 \%$ and $38.1 \%$ lower than martensitic stainless steel.

\subsection{Steady state thermal analysis of disc brake}

In case of braking system when brakes are applied, frictional heat is generated in the brake rotor due to which high temperatures are encountered. This frictional heat due to high temperature causes non-uniform spatial distribution called as hot spotting which contributes to fatigue and wear and in turn cracks [28,29]. This heat needs to be dissipated across the brake rotor to withstand repetitive braking conditions. So, in steady state thermal analysis [30], the overall temperature distribution and total heat flux is calculated. The boundary conditions for steady state thermal analysis $[31,32]$ is as shown in Figure 8. Once the boundary conditions are applied then temperature and total heat flux analysis have been performed. The frictional force between the disc and pad have been studied considering steady state thermal analysis [33].

Figure 9 shows the comparison of temperature distribution for Stainless steel and Grey cast iron. From this figure it is observed that the maximum temperature is $300^{\circ} \mathrm{C}$ in both the cases of stainless steel and grey cast iron and the minimum temperature is $244.25^{\circ} \mathrm{C}$ and $270.95^{\circ} \mathrm{C}$ in case of stainless steel and grey cast iron respectively. 


\section{Equivalent Elastic Strain}

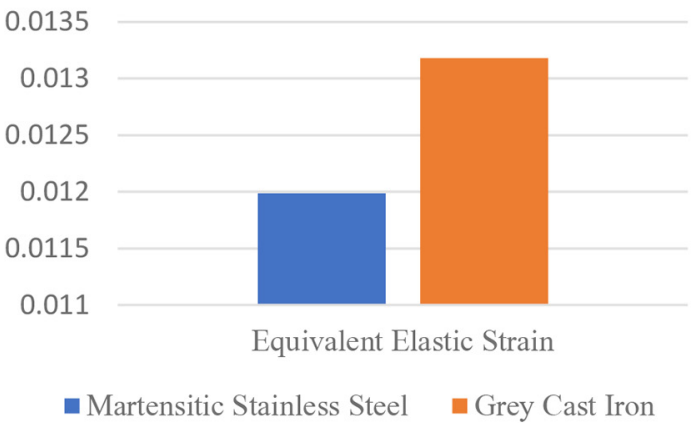

Shear Stress

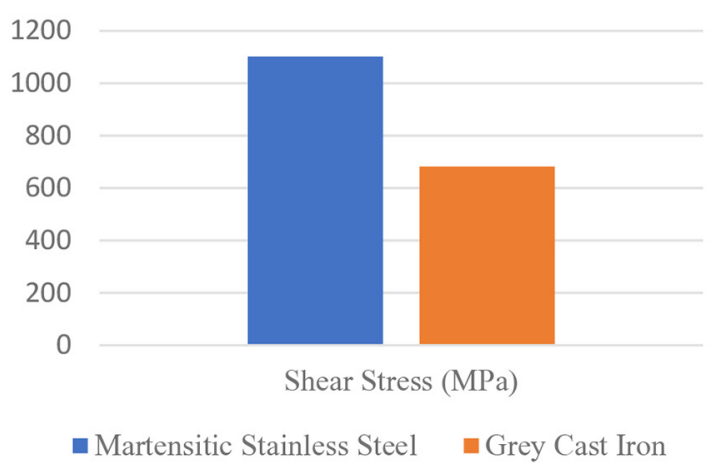

\section{Equivalent Stress}

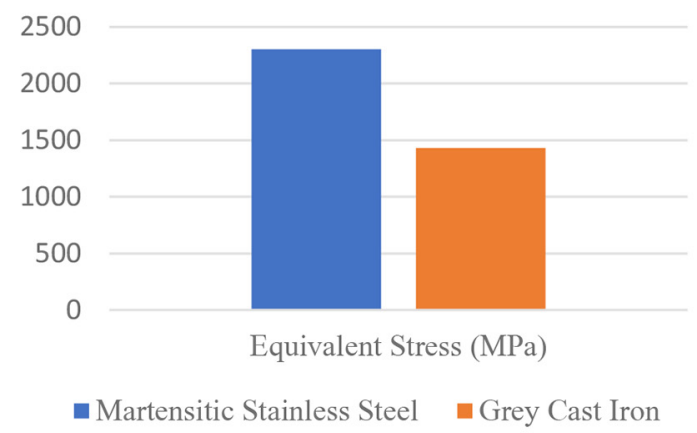

Total Deformation

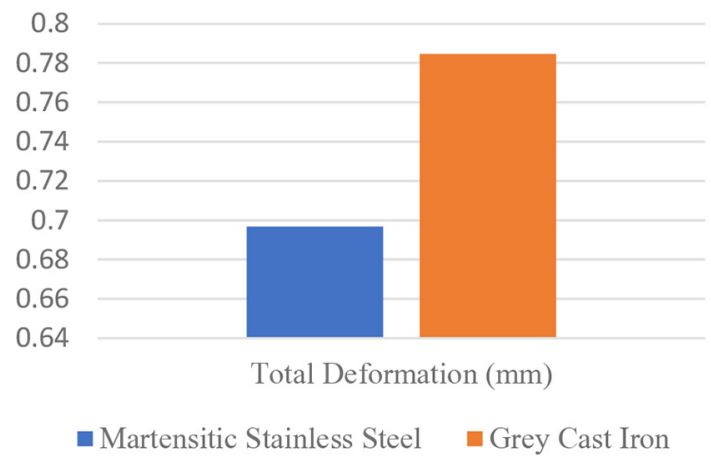

Fig. 7. Comparison of Equivalent strain, Equivalent stress, Shear stress and Total deformation for SS and GCI.

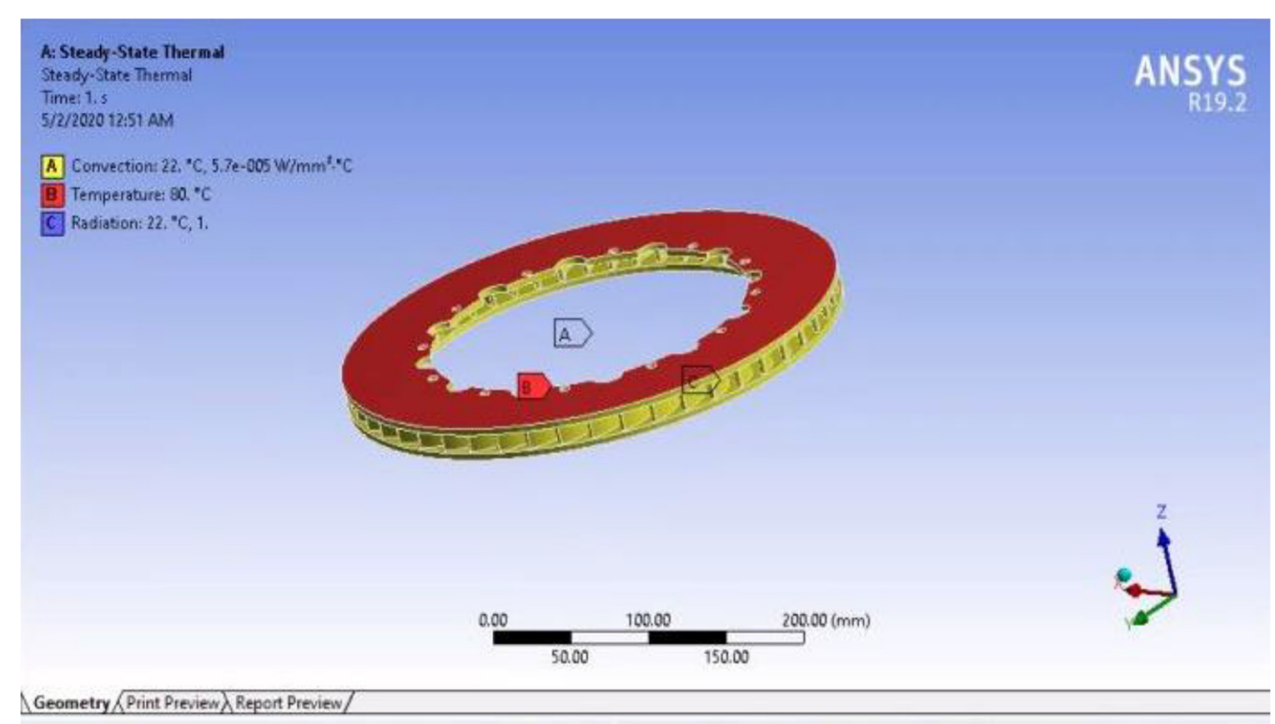

Fig. 8. Boundary conditions for steady state thermal analysis.

Figure 10 shows the comparison of total heat flux for stainless steel and grey cast iron. From this figure it is observed that the total heat flux value is $0.4629 \mathrm{~W} / \mathrm{mm}^{2}$ and $0.50468 \mathrm{~W} / \mathrm{mm}^{2}$ for stainless steel and grey cast iron. From this figure it can be concluded that heat transfer is more in case of grey cast iron as compared to stainless steel.
Similarly, the minimum total heat flux is $0.0008081 \mathrm{~W} / \mathrm{mm}^{2}$ and $0.00102 \mathrm{~W} / \mathrm{mm}^{2}$ for stainless steel and grey cast iron respectively.

Figure 11 shows the comparison of temperature and total heat flux for stainless steel and grey cast iron. From this figure it is observed that minimum temperature in 

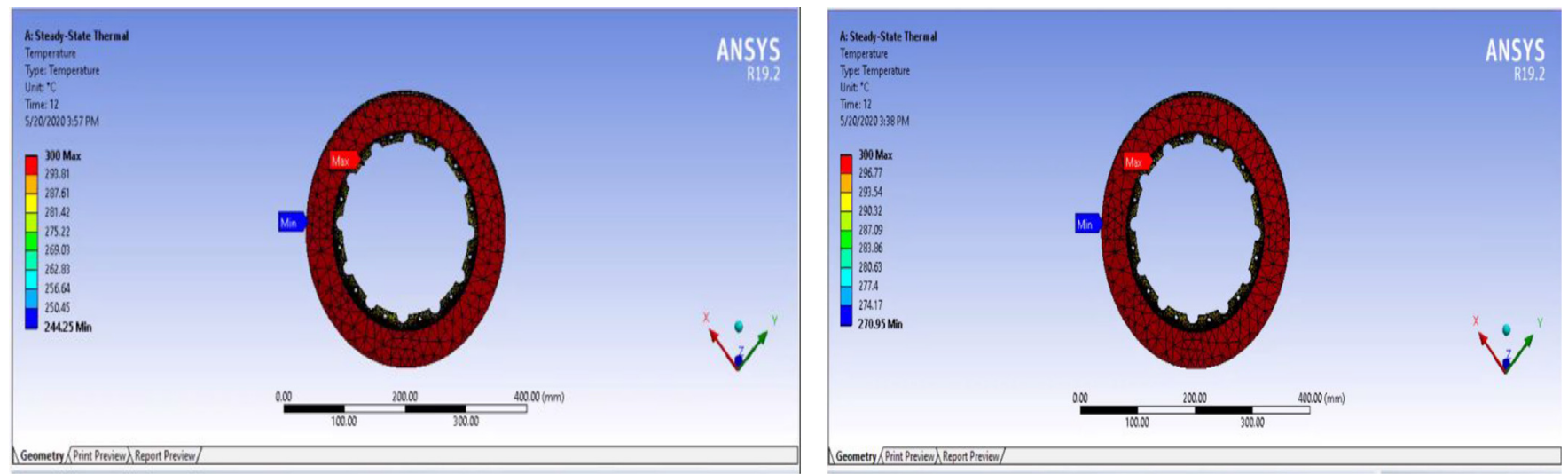

Fig. 9. Comparison of temperature distribution for SS and GCI.
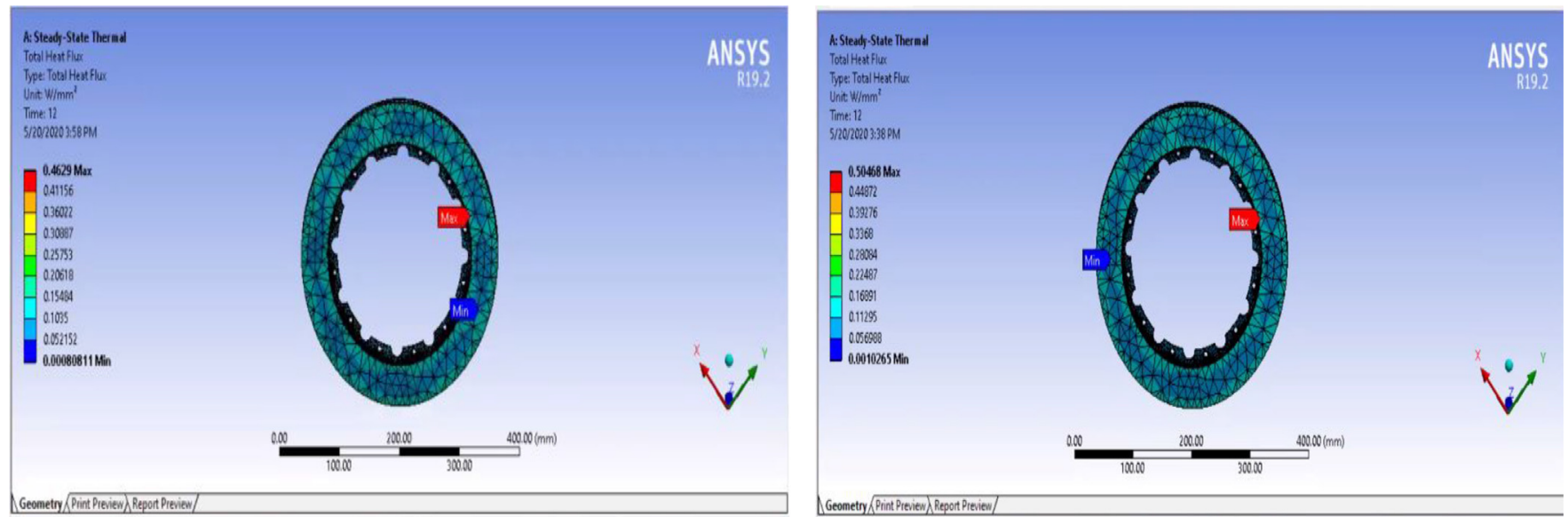

Fig. 10. Comparison of Total Heat Flux for SS and GCI.

Temperature ${ }^{\circ} \mathrm{C}$
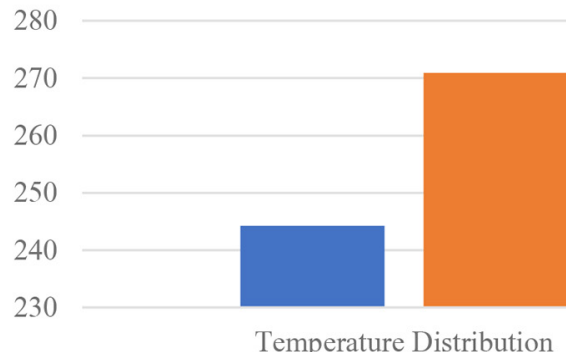

- Martensitic Stainless Steel $\quad$ Grey Cast Iron
Heat Flux

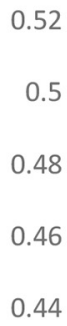

0.5
0.48
0.46
0.44

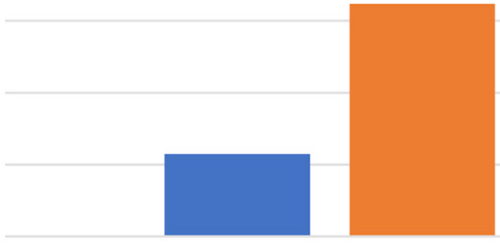

Total Heat Flux

- Martensitic Stainless Steel $\square$ Grey Cast Iron

Fig. 11. Comparison of temperature and heat flux for SS and GCI.

case of grey cast iron is $10.9 \%$ higher as compared to stainless steel. Whereas total heat flux (amount of heat dissipation) in case of grey cast iron is $9.02 \%$ higher as compared to stainless steel. Hence it can be concluded that gray cast iron provided good thermal and mechanical behavior [26,34]. The steady state thermal analysis of disc brake system indicates that if the temperature and friction are higher then the efficiency of the brake system reduces which has been justified in other references [35]. 


\section{Conclusion}

In this research paper design and analysis of 17 -inch brake rotor has been performed. The modelling is done using solid works and the analysis have been performed using Ansys considering static structural analysis and steady state thermal analysis. In case of static structural analysis, the maximum strain, stress, shear stress and total deformation has been studied whereas in case of steady state thermal analysis, total temperature and heat flux analysis have been studied. From this the following conclusions can be drawn.

- From static structural analysis it is observed that, the maximum strain and total deformation is less in case of stainless steel as compared to grey cast iron whereas maximum stress is less in case of grey cast iron in comparison with stainless steel. Also, the shear stress is less in case of grey cast iron as compared to stainless steel.

- From static structural analysis it is observed that equivalent strain and total deformation in case of grey cast iron is $9.96 \%$ and $12.6 \%$ higher than martensitic stainless steel whereas equivalent stress and shear stress in case of grey cast iron is $38 \%$ and $38.1 \%$ lower than martensitic stainless steel.

- From steady state thermal analysis, it can be concluded that the temperature distribution remains same in case of both stainless steel and grey cast iron whereas the heat distribution (Total heat flux) is more in case of grey cast iron as compared to stainless steel. It is observed that minimum temperature in case of grey cast iron is $10.9 \%$ higher as compared to stainless steel. Also, the total heat flux is $9.02 \%$ higher in case of grey cast iron as compared to stainless steel.

- From this analysis it can be concluded that both the materials have a similar price range in the market and stainless steel is having a slight advantage over grey cast iron because of its higher corrosion properties. Grey cast iron has a better option since it has better thermal stability which is considered most important in design of high-speed brake rotor.

\section{References}

1. W. Li, X. Yang, S. Wang, J. Xiao, Q. Hou, Comprehensive analysis on the performance and material of automobile brake discs, Metals 10, 1-18 (2020)

2. P. Filip, Friction Brakes for Automotive and Aircraft, Encyclopedia of Technology (Springer, Boston, MA, 2013)

3. H.S. Qi, A.J. Day, Investigation of disc/pad interface temperatures in friction braking, Wear 262, 505-513 (2007)

4. A. Borowski, Common methods in analyzing the tribological properties of brake pads and discs - a review, Acta Mech. Autom. 13, 189-199 (2019)

5. P. Liu, H. Zheng, C. Cai, Y. Wang, C. Lu, K.H. Ang, G.R. Liu, Analysis of disc brake squeal using the complex eigenvalue method, Appl. Acoust. 68, 603-615 (2007)
6. S. Subhasis, P.P. Rathod, A.J. Modi, Research paper on modelling and simulation of Disc brake to analyze temperature distribution using FEA, Int. J. Sci. Res. Dev. 2, 491-494 (2014)

7. N. Idusuyi, I. Babajide, O.K. Ajayi, T.T. Olugasa, A computational study on the use of an Aluminium metal matrix composite and Aramid as alternative brake disc and brake pad material, J. Eng. 2014, 1-6 (2014)

8. G. Ganesan, S. Magibalan, S. Gokul, K.P. Gopalakrishnan, S. Packayiraj, Design and fabrication of disc brake by using aluminum metal matrix composites, J. Emerg. Technolog. Innov. Res. 4, 77-81 (2017)

9. M.H. Dakhil, A.K. Rai, P.R. Reddy, A.A.H. Jabbar, Design and structural analysis of disc brake in automobiles, Int. J. Mech. Product. Res. Dev. 4, 95-112 (2014)

10. D.K. Dhir, Thermo-Mechanical performance of automotive disc brakes, Mater. Today Proc. 1, 1864-1871 (2018)

11. A. Belhocine, M. Bouchetara, Temperature and thermal stresses of vehicles gray cast iron, J. Appl. Res. Technol. 11, 674-682 (2013)

12. M. Nouby, J. Abdo, D. Mathivanan, K. Srinivasan, Evaluation of disc brake materials for squeal reduction, Tribol. Trans. 4, 644-656 (2011)

13. R. Bhat, K.S. Lee, Optimization of brake parameters for a disc brake system to improve the heat dissipation using Taguchi method, Int. J. Mech. Eng. Technol. 8, 44-52 (2017)

14. M. Vidiya, B. Singh, Experimental and numerical thermal analysis of formula student racing car disc brake design, J. Eng. Sci. Technol. Rev. 10, 138-147 (2017)

15. M. Chopade, A. Valavade, Experimental investigation using CFD for thermal performance of ventilated disc brake rotor, Int. J. Autom. Technol. 18, 235-244 (2017)

16. A.A. Yevtushenko, M. Kuciej, Temperature and thermal stresses in a pad/disc during braking, Appl. Therm. Eng. 30, 354-373 (2009)

17. P. Grzes, Maximum temperature of the disc during repeated braking applications, Adv. Mech. Eng. 11, 1-13 (2019)

18. G.L. Gigan, Improvement in the brake disc design for heavy vehicles using parametric evaluation, Proc. Inst. Mech. Eng. D 231, 1989-2004 (2017)

19. A.A. Yevtushenko, P. Grzes, Initial selection of disc brake pads material based on the temperature mode, Materials (Basel) 13, 822 (2020)

20. A.A. Yevtushenko, P. Grzes, Adamowicz, The temperature mode of the carbon-carbon multi-Disc brake in the view of the interrelations of its operating characteristics, Materials 13, $1-16(2020)$

21. R.A. Garcia-Leon, E. Florez-solana, Dynamic analysis of three autoventilated disc brakes, Ingenieria e investigacion 37, 102-114 (2017)

22. V.T. Nguyen, P. Dufrenoy, P. Coorevits, Simulation of energy dissipation and heat transfers of a braking system using the discrete element method: role of roughness and granular plateaus, J. Heat Transfer 142, 1-8 (2020)

23. O. Aranke, W. Algenaid, S. Awe, S. Joshi, Coatings for automotive grey cast iron bake discs: a review, Coatings $\mathbf{9}$, $1-27(2019)$

24. T. Faramarz, J. Salman, Analysis of heat conduction in a disk brake system, Heat Mass Transfer 45, 1047-1059 (2009)

25. A. Rashid, Overview of Disc brakes and related phenomena a review, Int. J. Vehicle Noise Vibr. 10, 257-301 (2014) 
26. A. Belhocine, W.Z.W. Omar, A numerical parametric study of mechanical behavior of dry contact slipping on the disc-pads interface, Alexandria Eng. J. 55, 1127-1141 (2016)

27. B.P. Sethupathi, A. Muthuvel, N. Prakash, S.W. Louis, Numerical analysis of a rotor disc for optimization of disc material, J. Mech. Eng. Autom. 5, 5-14 (2015)

28. G.L. Gigan, M. Ekh, T. Vernersson, R. Lunden, Modelling of gray cast iron for applications to brake discs for heavy vehicles, Proc. Inst. Mech. Eng. D 231, 35-49 (2016)

29. G. Ceuva, A. Sinatora, W.L. Guesser, Tschiptschin, Wear resistance of cast irons used in brake disc rotors, Wear $\mathbf{2 5 5}$, $1256-1260$ (2003)

30. A. Belhocine, A.R.A.B. Bakar, M. Bouchetara, Thermal and structural analysis of disk brake assembly during single stop braking event, Aust. J. Mech. Eng. 14, 26-38 (2016)
31. R. Vijay, L. Singaravelu, R. Jayaganthan, Development and characterization of stainless steel-fiber based copper-free brake liner formulation: a positive solution for steel fiber replacement, Friction 1, 25 (2019)

32. A. Belhocine, M. Bouchetara, Thermomechanical modelling of dry contacts in automotive disc brakes, Int. J. Therm. Sci. 60, 161-170 (2012)

33. H. Heerok, M.-S. Kim, H.-Y. Lee, N.-T. Jeong, H. Moon, E.-S. Lee, H. Kim, M. Suh, J.-d. Chung, J.H. Lee, The thermo-mechanical behavior of brake discs for high-speed railway vehicles, J. Mech. Sci. Technol. 33, 1711-1721 (2019)

34. K. Hakan, T. Ersin, Experimental study on braking and stability performance during low speed braking with ABS under critical load conditions, Eng. Sci. Technol. 24, 1224-1238 (2021)

35. M. Saleh, M. Mohammad, A comparative study between ABS and disc brake system using finite element method, Hal-01624015 1-17 (2017)

Cite this article as: Anil Babu Seelam, Nabil Ahmed Zakir Hussain, Sachidananda Hassan Krishanmurthy, Design and analysis of disc brake system in high speed vehicles, Int. J. Simul. Multidisci. Des. Optim. 12, 19 (2021) 